\title{
Power Supply Regulation Systems Installed in the Fermilab Accelerators
}

\author{
S. Hays, D. Wolff and H. Pfeffer \\ Fermi National Accelerator Laboratory \\ P.O. Box 500, Batavia, Illinois 60510
}

November 1991

* Presented at the IEEE Nuclear Science Symposium, Santa Fe, New Mexico, November 2-8, 1991. 


\section{Disclaimer}

This report was prepared as an account of work sponsored by an agency of the United States Government. Neither the United States Government nor any agency thereof, nor any of their employees, makes any warranty, express or implied, or assumes any legal liability or responsibility for the accuracy, completeness, or usefullness of any information, apparatus, product, or process disclosed, or represents that its use would not infringe privately owned rights. Reference herein to any specific commercial product, process, or service by trade name, trademark, manufacturer, or otherwise, does not necessarily constitute or imply its endorsement, recommendation, or favoring by the United States Government or any agency thereof. The views and opinions of authors expressed herein do not necessarily state or reflect those of the United States Government or any agency thereof. 


\title{
POWER SUPPLY REGULATION SYSTEMS INSTALLED IN THE FERMILAB ACCELERATORS
}

\author{
S. Hays, D. Wolff, H. Pfeffer \\ FERMI NATIONAL ACCELERATOR LABORATORY \\ Box 500 \\ Batavia III. 60510
}

\begin{abstract}
A variety of current and voltage regulation systems have been installed in the Fermilab large magnet system. The four major systems employ different methods to achieve the desired degree of regulation. The methods include computer control and feedback, adaptive learning, precision (10ppm) current monitoring, and the use of feed-forward signals. This paper will explain each method used and present the measured regulation of the above systems. Also an overview of planned upgrades and improvements will be presented.
\end{abstract}

\section{INTRODUCTION}

The need for higher resolution and stability in power supply current regulation is becoming more necessary for accelerator physics. One step to developing new and better systems is to understand the limitation of the existing types now in operation. There are four different regulation system types installed in Fermilab's two main accelerators. They all have the same goal of current regulation but each has its own unique load and tracking requirement which has stimulated the need for the different types of control. The Tevatron regulation system controls the four mile Tevatron superconducting magnet string; the Main Ring system controls the four mile conventional magnet strings; the Low Beta systems control the Tevatron interaction regions magnets; and the Overpass systems control the magnets that bypass the main ring proton beam around the Tevatron interaction regions.

\section{TEVATRON REGULATION}

The FERMILAB Tevatron power supply system consists of 12 distributed voltage regulated, 850 volt power supplies connected to a $\mathbf{3 7}$ Henry load. Ten of the voltage regulated supplies are $2.8 \mathrm{MVA}$ each, and are used as ramping voltage sources. The other two are 5 MVA supplies of which one is used as a regu-

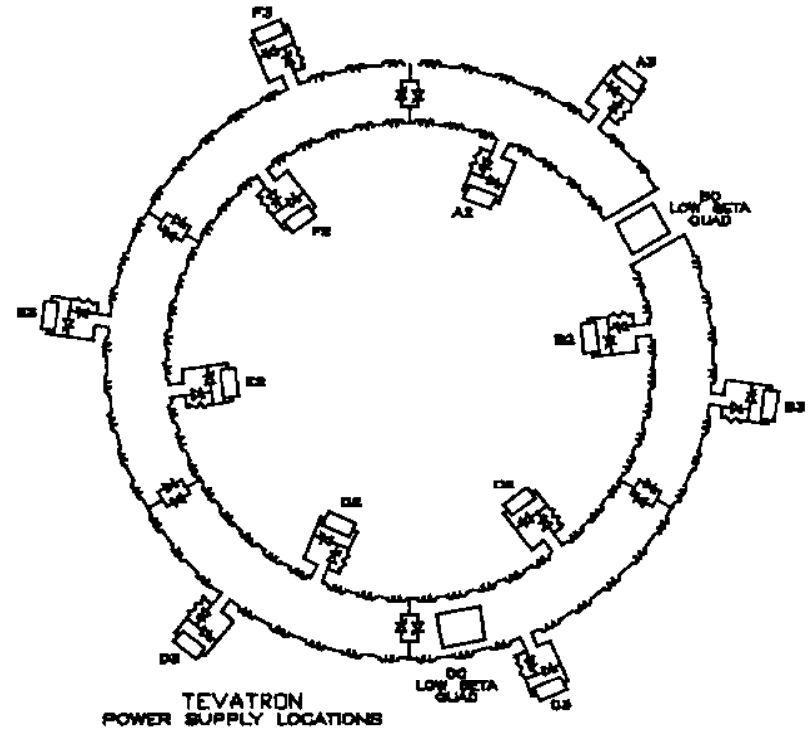

lator, the other for ramping. This system ramps from 400 to 4400 amps over a 60 second cycle in fixed target mode or holds at 4400 amps for up to 18 hours in collider operation.

The current regulation system starts with a ramp generating computer, which provides the feedforward voltage waveforms to the 12 power supplies. The ramp generating computer ${ }^{1}$ also provides a current reference waveform to a temperature regulated "24 bit" Digital to Analog converter. This "24 bit" DAC is constructed using an ultra stable ANALOGIC 16 bit DAC combined with an 8 bit DAC, which theoretically yields the 24 bits. This high resolution is desired to minimize the size of the voltage steps out of the regulating power supply during ramping. The combined DAC output and the current signal from a temperature regulated D.C. Current Transformer (DCCT) are subtracted to generate the "current error signal" which is sent to the regulating power supply in an analog format. This signal is used to close a real time feedback loop with a bandwidth of $10 \mathrm{~Hz}$. Both the DAC and the burden resistor of the DCCT are temperature regulated in an oven operating at $380 \mathrm{C}$.

Work supported by the U.S. Department of Energy under contract No. DE-AC02-76CHO300O. 


\section{MEASUREMENTS}

Measurements on the 24 bit DAC have shown a maximum resolution of 21 bits; the lower three bit are masked by the noise level of the electronics. The 21 bit capability represents a resolution of $0.5 \mathrm{ppm}$.

Current measurements made during $800 \mathrm{Gev}$ operation (3550 amps) are shown below where the full scale (F.S.) value is 5000 amps.

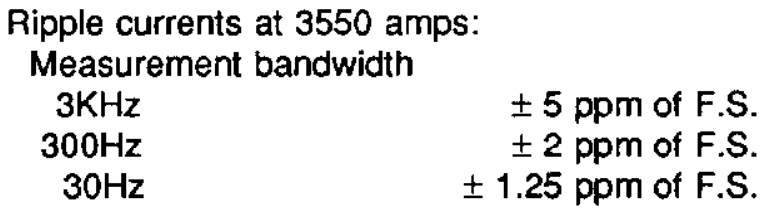

These numbers are on the order of the inherent transductor noise.

Ramp-to-Ramp Variation at 3550 flattop:

$15 \mathrm{~Hz}$ Measurement bandwidtht. $.3 \mathrm{ppm}$ of F.S.

Long Term Drift:

The DC current during collider mode operation was measured periodically over a three months using a second DCCT and was found to have a stability of: \pm 5 ppm of F.S.

Tracking of the Ramp Reference: $15 \mathrm{~Hz}$ Measurement bandwicttro ppm of F.S.

Absolute Current Accuracy: $\quad \pm .1 \%$ The absolute accuracy of the current regulation systems have not been of large concern to operation. The beam position is controlled by small correction devices and tends to be empirically tuned.

\section{MAIN RING SYSTEM}

The Fermilab Main Ring power supply system consist of twenty five 2.8 MVA voltage regulated power supplies on the bend bus and eleven 2.8 MVA supplies on the two quad buses. Regulation is controlled by two task sharing computers which have control of all 35 supplies over a serial link running at $10 \mathrm{Mega}$ bits/second. These computers generate feedforward voltage waveforms and current references much like the Tevatron computer. The feedforward control of the twenty four bend bus supplies is divided into four groups of six supplied which are ramped in sequence rather than all together. This method is a compromise involving consideration of reactive power, low current ripple and passive filter characteristics. The power supply voltage reference update rate is $720 \mathrm{~Hz}$.
The computers send the bend bus current reference waveform to a 16 bit ANALOG DEVICES DAC. The signal from a 5,000 amp HOLEC DCCT is subtracted from the DAC output and amplified to generate an error signal. This signal is read by the computers which use it to provide adaptive correction to all of the supplies and direct feedback to the regulator ${ }^{2}$. The adaptive correction consist of using the error signal to form a corrective waveform that learns from one machine cycle and corrects the next. This technique extends the bandwidth of the system, and enables it to regulate rapidly changing current waveforms.

The two Quadrupole buses each run at $\approx 92 \%$ of the bend bus and are regulated using 300 amp transductors that measure the difference between each quad bus current and the bend bus current. This is accomplished by using a coaxial bus arrangement with the quadrupole and bend currents flowing in opposite directions through the transductor head.

\section{MEASUREMENTS}

The Main Ring is ramped to two different levels; 120 Gev level (1350 amps) with a 2.4 second cycle for antiproton production and $150 \mathrm{Gev}$ level (1700 amps) with a 54 second cycle for Tevatron injection. The injection level from the booster accelerator is $8 \mathrm{Gev}$ (90 amps).

Regulation at injection: 90 amps $720 \mathrm{~Hz}$ Measurement bandwidth

$\begin{array}{ll}\text { Bend Bus: } & \pm 300 \mathrm{ppm} \\ \text { Quad Vertical Bus: } & \pm 200 \mathrm{ppm} \\ \text { Quad Horizontal Bus: } & \pm 370 \mathrm{ppm}\end{array}$

Regulation at 120 Gev Flattop: 1350 amps $720 \mathrm{~Hz}$ Measurement bandwidth

$\begin{array}{ll}\text { Bend Bus: } & \pm 40 \mathrm{ppm} \\ \text { Quad Vertical Bus: } & \pm 60 \mathrm{ppm} \\ \text { Quad Horizontal Bus: } & \pm 44 \mathrm{ppm}\end{array}$

Regulation at 150 Gev Flattop: 1700 amps $720 \mathrm{~Hz}$ Measurement bandwidth Bend Bus: $\pm 60 \mathrm{ppm}$

Tracking during ramping: $720 \mathrm{~Hz}$ Measurement bandwidth Bend Bus:

Through Flattop $\pm 80 \mathrm{ppm}$ Including invert $\pm 450 \mathrm{ppm}$ Absolute Current Accuracy $\pm .01 \%$ of reading (HOLEC Transductor Spec.) 


\section{LOW BETA SYSTEM}

This $10 \mathrm{ppm}$ regulation system was constructed to be used on ramping superconducting magnet loads but is applicable to conventional magnet power systems. The system consist of a commercial 10ppm transductor used to measure the magnet current and then provide the necessary feedback signals to close a current loop around a voltage regulated supply. This system is intended to be used as a stand alone package connected to a . $1 \%$ voltage regulated power supply. The transductor electronics, DAC reference and subtraction electronics, as now installed, use a temperature regulated water cooler and circulation pump to provide a constant temperature environment. The water cooling is provided by a stand alone, cool only refrigerator circulation system manufactured by NESTLAB. This system was installed as an upgrade to existing power supplies with the goal to provide a standard package for use in many application and lower the need for unique spare parts for each supply.

Magnet load compensation is provided for in the regulator and includes Proportional plus Derivative (PD) feedforward signals if needed for faster ramping devices. Additional features provided are slow start, over current detection, out of regulation beam abort signals and local voltage mode control for testing.

To provide the most accurate reference signal, the current reference is received by the regulator on a 16 bit strobed data bus. To provide slew rate limiting without introducing additional errors, the digital reference data lines are intercepted and the slew rate function is performed by a single chip micro controller before the data is sent to the DAC module. This micro controller also provides local current or open loop voltage reference control and has a built in ramp generator for local testing.

The current regulator is packaged in a 3U high 19" wide EURO sub rack with modular cards and plug-in units for ease of maintenance and repair. The $10 \mathrm{ppm}$ transductors used are also 19" rack mounted manufactured by either HOLEC or DANFYSIK. There are 5 independent regulation loops installed in each of the interaction regions which all share the one local water system.

The DAC module contains a 16 bit ANALOGIC MP. -8116-1 Digital to Analog converter and the accurate subtraction circuits necessary for regulation. This module also provides high quality outputs to the rear panel for monitoring the current and reference signals during operation. These monitors are used in the FNAL system with a $6 \frac{1}{2}$ digit DATRON meter connected to a CAMAC based IEEE-488 interface for data logging in the main control room.

With a secondary goal of constructing a "standard package" current regulation system, two types of $42 \mathrm{HP}$
DAC modules have been constructed. One which uses chilled water and an external closed loop water system for use when there is more than one installed in a single location and the second uses a thermoelectric cooler for single loop operation.

\section{GAIN LOWERING CIRCUIT}

Four of the Low Beta Quad power supplies, for which these current regulators were built, have reversing switches installed. The reversing switches require a ramp to zero current for switching and during this time the supply must remain stable but the regulation need not be as accurate. The nonlinearity as a result of the switch S.C.R.s cause a low current loop instability. We have chosen to use gain adjustment based on reference levels in order to maintain stability. When the reference level ramps below 100 amps the current loop gain is ramped down by a factor of 5 and ramps back up when the reference exceeds 50 amps after the switching.

\section{MEASUREMENTS}

The long term measurements were made using the IEEE-488 interface and DATRON meter connected to a data logger. The ramped data was taken during fixed target operation using a Tek AM502 differential amplifier with a selectively adjustable bandwidth. The full scale below (F.S.) represents 7,500 amps.

Regulation at injection: 216 amps

15 Measurement bandwidth $\pm 2 \mathrm{ppm}$ of F.S. $120 \mathrm{~Hz}$ ripple current $\quad \pm 3 \mathrm{ppm}$ of F.S.

Drift during $20 \mathrm{hr}$. store: 216 amps

@ $150 \mathrm{Gev}$ injection $\quad \pm .3 \mathrm{ppm}$ of F.S.

800 Gev ramping: 1160 amps $100 \mathrm{~Hz}$ Measurement bandwidth

$\begin{array}{lr}\text { Flattop } & \pm 1.5 \mathrm{ppm} \text { of F.S. } \\ \text { Ramp up } & \pm 50 \mathrm{ppm} \text { of F.S. } \\ \text { Ramp down } & \pm 130 \mathrm{ppm} \text { of F.S. }\end{array}$

Ramp to Ramp variation: $\quad \pm .3 \mathrm{ppm}$ of F.S.

\section{OVERPASS SYSTEM}

The Main Ring beam path moves above the collider detectors at two locations in the accelerator. This move requires vertical bends as well as a higher radial bend inward. The inward bend is required to keep the path length the beam has to travel around the accelerator the same as the original design. The vertical bending magnets and an equal number of horizontal bending 


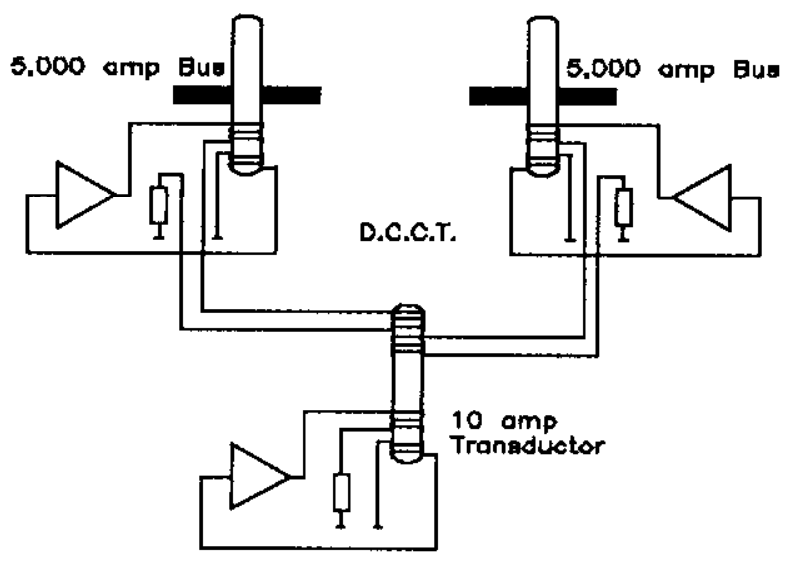

magnets run at twice the main ring current $(3,400$ amps). This bending field must track the main ring field to $0.1 \%$, because the RF system corrects for momentum errors during the ramp at only one physical location $^{3}$.

The tracking method used is to install three transductors, one on the main ring bus, one on the bus to be regulated and the third used to subtract the burden resistor currents of the first two. Using a turns ratio of $14: 7$ wound on the core of the third 10 amp transductor allowed for the subtraction and gain adjust without adding more drift components into the regulation loop. The main ring transductor is also used to provide a current reference to the system. This reference is used to generate and provide a feedforward signal for the power supply.

$$
V_{\text {output }}=i R+L \frac{d i}{d t}+K \frac{d^{2} i}{d t^{2}}
$$

A small correction program injected to allow the Main Control Room to offset the overpass current in order to adjust the position of the main ring beam.

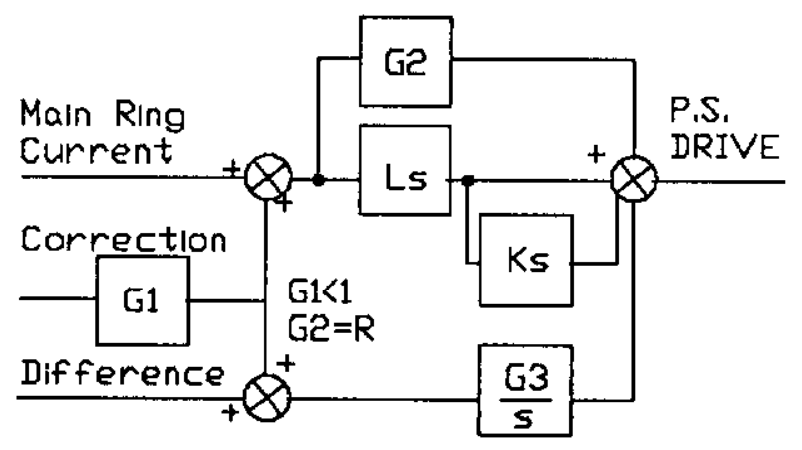

\section{MEASUREMENTS}

The following measurements were made during ramping using a Tektronix Am502 differential amplifier set to a bandwidth of $100 \mathrm{~Hz}$.

Regulation at injection: 180 amps $\pm 556 \mathrm{ppm}$

Regulation at 120

Gev Flattop: 2700 amps $\quad \pm 74$ ppm

Regulation at 150

Gev Flattop: 3400 amps $\quad \pm 75$ ppm

Ramp up

$\pm 150 \mathrm{ppm}$

Ramp down $\quad \pm 520 \mathrm{ppm}$

\section{IMPROVEMENTS}

Planed improvements to the Main Ring system include the replacement of the existing adaptive control computers with 68040 VME based computers. This new system will use a processor for each bus and will include a circular buffer for recording many of the control and monitoring signals. As part of this upgrade eight new $10 \mathrm{ppm}$ transductors and a $10 \mathrm{ppm}$ current regulator of the type described above will be installed.

An additional improvement to the power supply systems will be to standardize the voltage regulators. The present maintenance load require by the many different power supplies which each have a unique regulation system, is large in both manpower and spare parts. The voltage regulator will have available voltage monitors, filter compensation, DAC and analog reference inputs, fast bypass failure checking and a serial link interface for multiple supply control.

\section{REFERENCES}

1. O. Calvo UNLP Argentina/Fermilab R. Flora, $M$. Macpherson Fermilab, "MULTIPROCESSOR CONTROL AND REGULATION OF THE TEVATRON POWER SUPPLIES"

2. H. Pfeffer and D. Jong Fermi National Accelerator Laboratory, Batavia II. "FERMILAB MAIN RING POWER SUPPLY CONTROL PROGRAMS". IEEE TRANSACTIONS ON NUCLEAR SCIENCE Vol.NS-24, No.3, June 1977.

3. W. Merz and H. Pfeffer "THE FERMILAB DO OVERPASS POWER SUPPLY SYSTEM". PARTICAL ACCELERATOR CONFERENCE May 1985. 